\title{
Analysis of Spatial-Temporal Variation of Agricultural Drought and Its Response to ENSO over the Past 30 Years in the Huang-Huai-Hai Region, China
}

\author{
Yan Huang ${ }^{1,2}$, Qingjiu Tian ${ }^{1,2, *}$, Lingtong Du ${ }^{1,2}$, and Shaojie Sun ${ }^{1,2}$ \\ ${ }^{1}$ International Institute for Earth System Science, Nanjing University, Nanjing, Jiangsu, China \\ ${ }^{2}$ Jiangsu Provincial Key Laboratory of Geographic Information Science and Technology, \\ Nanjing University, Nanjing, Jiangsu, China
}

Received 31 October 2012, accepted 30 January 2013

\begin{abstract}
This study constructed a time series of the seasonal Temperature Vegetation Dryness Index (TVDI) based on a remotely sensed dataset from the National Oceanic and Atmospheric Administration/Advanced Very High Resolution Radiometer (NOAA/AVHRR) and Earth Observing System/Moderate Resolution Imaging Spectroradiometer (EOS/MODIS). We examined the spatiotemporal variation in drought in the Huang-Huai-Hai region of China during the period from 1981 to 2011. Combined with the El Niño and southern oscillation (ENSO) indicator (i.e., the Sea Surface Temperature Anomaly, SSTA of the El Niño 3.4 area), the spatial and temporal relationship of agricultural drought in this region and ENSO was analyzed. The results showed that drought demonstrated a significant downward trend (95\% confidence level) which covered $38.01 \sim$ $55.13 \%$ of the farmland in this region. In addition, the largest area of drought reducing appeared in winter. The significant decreasing tendency of agricultural drought started from the late $20^{\text {th }}$ and early $21^{\text {st }}$ centuries, whose variation cycles were mainly between 2.5 to 5 a (year). TVDI series were closely correlated to the ENSO index sequences at the 2.5 to 7 a cycle, and there was a delay from 0.16 to 1.40 a between them. However, the correlation between TVDI and ENSO index series was less. These findings show that there is a relationship between the spatiotemporal changes of agricultural drought in the Huang-Huai-Hai region of China and ENSO events over the recent 30 years.
\end{abstract}

Key words: TVDI, ENSO, Agricultural drought, AVHRR, MODIS

Citation: Huang, Y., Q. Tian, L. Du, and S. Sun, 2013: Analysis of spatial-temporal variation of agricultural drought and its response to ENSO over the past 30 years in the Huang-Huai-Hai region, China. Terr. Atmos. Ocean. Sci., 24, 745-759, doi: 10.3319/TAO.2013.01.30.01(Hy)

\section{INTRODUCTION}

Drought is one of the most serious natural disasters around the world, with a much higher occurrence frequency and larger influence on people than other natural calamities. It also has the most far-reaching negative impacts to ecological environment and social economy, especially to agricultural production. The production of food crops such as rice, corn and wheat in many parts of Asia, according to the Intergovernmental Panel on Climate Change (IPCC) is affected by increased drought (Bates et al. 2008). As far as China is concerned, the average annual drought affected area and disaster area are $2.16 \times 10^{7} \mathrm{hm}^{2}$ and $9.56 \times 10^{6} \mathrm{hm}^{2}$,

\footnotetext{
* Corresponding author

E-mail: tianqj@nju.edu.cn
}

respectively and the grain loss caused by drought is $1.58 \times$ $10^{10} \mathrm{~kg}$ from 1950 to 2008 (Weng and Yan 2010). Therefore, the occurrence and development pattern of drought plays a vital role in disaster forecast and prevention to minimize disaster. Traditional drought monitoring methods based on the on-site meteorological parameters and soil moisture observations has some disadvantages such as the number limitation and uneven distribution of observation sites, losing of regional information when points were used to represent regions, as well as high cost and time consuming. Remote sensing technology, with the advantages of real-time, rapid and large area monitoring, provides an effective means for large-scale monitoring and long time series spatiotemporal variation analysis of drought. Among numerous remotely sensed indices for drought monitoring, a water scarcity 
indicator for vegetation known as Temperature Vegetation Dryness Index (TVDI) has been used. It is a simplification of surface temperature-vegetation index space (Nemani et al. 1993; Moran et al. 1994; Sandholt et al. 2002) which effectively monitors the vegetation and soil moisture conditions (Patel et al. 2009; Chen et al. 2011) as well as agricultural drought in China (Qi et al. 2003; Sun et al. 2010). Therefore, this study aims to adopt TVDI to characterize the state of the agricultural drought in the research area over the past 30 years.

El Niño-Southern Oscillation (ENSO) is an irregular cycle of warming and cooling of the tropical eastern Pacific with attendant atmospheric and oceanic effects. El Niño is the warm phase of ENSO, which accompanies decreasing sea-level pressure difference between the western and eastern Pacific, weakening the Walker circulation (one of the world's most prominent and important atmospheric systems and closely linked to the mean-state of the equatorial Pacific Ocean.) (Power and Smith 2007) and the relaxation of the normally westward surface winds, while La Niña is the cool phase of ENSO and the converse El Niño (Sarachik and Cane 2010). ENSO is one of the strongest signals of atmosphere-ocean observed by humans, and is also considered as the most significant indicator of inter-annual climate change (Xu et al. 2009). Many studies have shown that the ENSO event acts as one of the reasons for triggering drought (Dai 2011). For instance, the North American Medieval megadroughts can be attributed to La Niña events (Seager et al. 2008). The long-term drought in western America in the second half of $19^{\text {th }}$ century was related to the La Niña event occurred between 1855 and 1863 (Cole et al. 2002). The severe droughts in Sahel from 1970s to 1980s were also caused by El Niño events and their changes (Folland et al. 1986; Giannini 2003, 2008). To date, it is generally agreed that the continuing droughts of Sahel result from large-scale sea surface temperature change ( $\mathrm{Ma}$ and $\mathrm{Fu}$ 2007). For other areas, however, whether drought formation is largely due to local land-atmosphere interaction or sea surface temperature changing forces is still controversial.

Several studies have focused on the relationship between drought in China and ENSO. Li and Yao (1991) found that drought occurred in the northern part of North China, eastern Inner Mongolia and northern Qinghai-Tibet Plateau when the 97 El Niño events occurred between 1472 and 1979. Li et al. (2010) studying drought and ENSO events in the range of 1950 to 2000 , pointed out that starting in the late 1970s, El Niño events led to the weakening of East Asia summer monsoon (EASM), which resulted in drought in eastern China. These studies have mainly used precipitation, meteorological drought index and statistical datasets on drought. Su and Wang (2007) used the Palmer Drought Severity Index (PDSI) to study the relationship of ENSO and variation in droughts and wet periods in China. $\mathrm{Lu}$ et al. (2006) analyzed the relationship between ratio of drought affected and disaster area of China and ENSO indices from 1948 to 1990. Unlike these indicators, remotely sensed drought indices can characterize the vegetation and soil moisture condition and directly reflect agricultural drought conditions caused by imbalance of soil water supply and vegetation water demand. Thus, to understand the relationship between agricultural drought and ENSO events based on remote sensing drought index, this study looked at the combined effects of climate and environment into consideration which are directly related to agricultural production. The focus of this study is to examine the response of the occurrence and development of agricultural drought to ENSO events on the basis of analysis of the variation trend, catastrophe and cycle characteristics of the long-term remotely sensed TVDI series.

\section{STUDY AREA}

The Huang-Huai-Hai region (Fig. 1) is located in northern China $\left(112-122^{\circ} \mathrm{E}, 32-41^{\circ} \mathrm{N}\right)$, acquiring its name from the Yellow River, Huaihe River and Haihe River flow through this region. It lies in the warm-temperate zone with continental monsoon climate, and the annual mean temperature, days of frost-free period and precipitation of this region are $10-15^{\circ} \mathrm{C}, 182-198 \mathrm{~d}$ and $500-600 \mathrm{~mm}$, respectively. There is large inter-annual and seasonal variation of precipitation here, which causes a large difference at 4 to 6 times between the rainy years and dry years. Summer precipitation accounts for over $60 \%$ of total annual precipitation, while the winter part is less than $5 \%$. The average elevation in this region is less than $50 \mathrm{~m}$, with alluvial plain as the main landform type, alluvial soil as the main soil type and the main land use is cultivated soil. This region is one of the top five major grain producing areas in China, with winter wheat (Triticum aestivum L.) and summer maize (Zea mays $L$.) in rotation, but it is also one of China's drought-prone areas. Due to the above reasons, this region has been chosen as the site for the study. The occurrence of drought in this region has obvious seasonal characteristics, the tendency and cycle of the drought index series of this region will be analyzed by each season as well.

\section{DATA AND METHODS}

\subsection{Drought Index}

The Temperature Vegetation Dryness Index (TVDI) was used to characterize agricultural drought, which was calculated by vegetation index and land surface temperature at a certain time according the following formula (Nemani et al. 1993; Moran et al. 1994; Sandholt et al. 2002).

TVDI $=\frac{T_{s}-T_{s_{\min }}}{T_{s_{\max }}-T_{s_{\min }}}$ 
where, $\mathrm{T}_{\mathrm{s}}$ is land surface temperature at each pixel; $\mathrm{T}_{\mathrm{s}_{\min }}=$ $a_{1}+b_{1}$ NDVI, which is the minimum surface temperature for a given NDVI (Normalized Difference Vegetation Index), corresponding to the 'wet edge' (maximum evapotranspiration and unlimited water access) in the $\mathrm{T}_{\mathrm{s}}$-NDVI characteristic space (as Fig. 2); $\mathrm{T}_{\mathrm{s} \max }=\mathrm{a}_{2}+\mathrm{b}_{2} \mathrm{NDVI}$, which is the maximum surface temperature for a given NDVI, corresponding to the 'dry edge' (limitation of water availability) in the $\mathrm{T}_{\mathrm{s}}$ NDVI characteristic space. $a_{1}, b_{1}, a_{2}$, and $b_{2}$ are the fitting coefficients of the formula of $\mathrm{T}_{\mathrm{s}_{\min }}$ and $\mathrm{T}_{\mathrm{s}_{\max }}$, as well as the intercepts and slopes of the wet edge and dry edge, respectively. The $\mathrm{T}_{\mathrm{s}}-\mathrm{NDVI}$ characteristic space is established by the relationship between $\mathrm{T}_{\mathrm{s}}$ and at each time. $\mathrm{NDVI}=(\mathrm{NIR}-$ Red $) /($ NIR + Red $)$, NIR is the near-infrared band and Red is the red band, corresponding to the $2^{\text {nd }}$ and $1^{\text {st }}$ band of the MOD09A1 remotely sensed image respectively. $\mathrm{T}_{\mathrm{s}_{\min }}$ and $\mathrm{T}_{\mathrm{s}_{\max }}$ were determined by establishing $\mathrm{T}_{\mathrm{s}}$-NDVI characteristic space with NDVI interval of 0.01 , then TVDI values were calculated. Higher values of TVDI indicate less soil moisture and drier vegetation, whereas lower values indicate more soil moisture and more normal vegetation conditions.

We used the 10-day composite of and the $4^{\text {th }}$ and $5^{\text {th }}$ band brightness temperature data from the NOAA/AVHRR satellite data product Pathfinder AVHRR Land (PAL) dataset to construct the monthly NDVI and $\mathrm{T}_{\mathrm{s}}$ series from August 1981 to September 2001. The land surface temperature was estimated by the split window algorithm (Becker and Li 1990). Surface emissivity, which was an intermediate variable in this split window algorithm, was calculated based on the relationship of the brightness temperature band and NDVI (Cihlar et al. 1997). Meanwhile, the 8-day composite reflectance product MOD09A1 and surface temperature data MOD11A2 from EOS/MODIS was used to obtain the monthly NDVI and $\mathrm{T}_{\mathrm{s}}$ series from March 2000 to June 2011. To obtain the monthly value of NDVI and $\mathrm{T}_{\mathrm{s}}$, the Maximum Value Composite (MVC) algorithm was employed (Holben 1986), rather than arithmetic mean. The MVC algorithm selects the maximum value on a per-pixel basis over a set compositing period and is designed to minimize atmospheric effects, including residual clouds (Holben 1986), which was both used for NDVI and $\mathrm{T}_{\mathrm{s}}$ compositing (Cihlar et al. 1994; Lambin and Ehrlich 1996). The relationships between AVHRR-NDVI, MODIS-NDVI and AVHRR-T and MODIS- $\mathrm{T}_{\mathrm{s}}$ was established using the overlapping part (totally 19 images) of the two kinds of the monthly datasets during the period between March 2000 and September

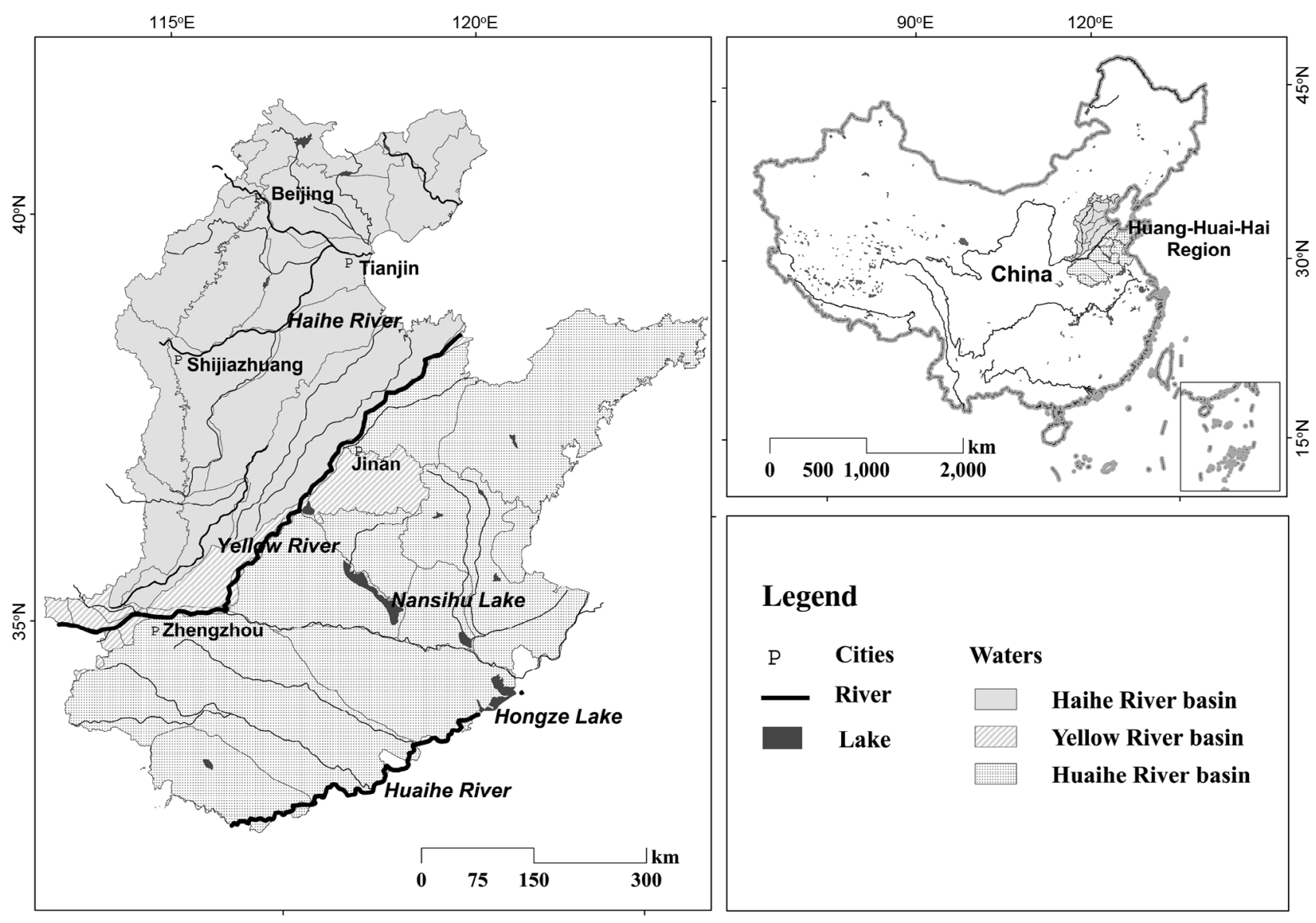

Fig. 1. Distribution of basins in the Huang-Huai-Hai region. 


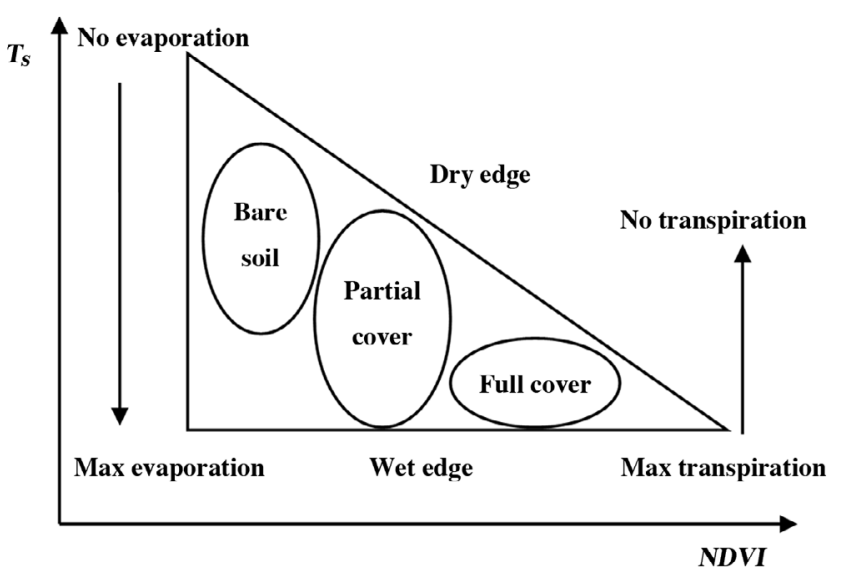

Fig. 2. Simplified $\mathrm{T}_{\mathrm{s}}$-NDVI characteristic space (Sandholt et al. 2002).

$2001\left(\mathrm{NDVI}_{\mathrm{MODIS}}=0.947 \mathrm{NDVI}_{\mathrm{AVHRR}}+0.216, \mathrm{r}=0.794\right.$ $(\mathrm{p}<0.01), \mathrm{N}=5.6 \times 10^{6}, \mathrm{~T}_{\text {sMOII }_{\text {Mon }}}=0.736 \mathrm{~T}_{\mathrm{s}_{\text {AVHRR }}}+8.246, \mathrm{r}=$ $0.781(\mathrm{p}<0.01), \mathrm{N}=5.6 \times 10^{6}, \mathrm{r}, \mathrm{p}$ and $\mathrm{N}$ indicates the correlation coefficient, significance level and number of the total pixels to construct the correlation, respectively). The AVHRR-NDVI and AVHRR- $\mathrm{T}_{\mathrm{s}}$ series between August 1981 and February 2000 were transferred into MODIS- and MODIS- $\mathrm{T}_{\mathrm{s}}$ series according to the correlation. The frequency histogram of the constructed NDVI and $\mathrm{T}_{\mathrm{s}}$ image series of each season was shown in Fig. 3. The monthly TVDI was calculated and the TVDI sequence from August 1981 to June 2011 was constructed. Finally, seasonal average series were constructed, with February to April as the spring, May to July as the summer, August to October as the autumn and November to the next January as the winter.
Nine MCD12Q1 images, the land cover type product of MODIS (1 scene per year) between 2001 and 2009 were used to extract the annual crop types and the intersection of which was used to mask all the TVDI series. This dataset was the revision of the IGBP (International Geosphere-Biosphere Programme) land cover type dataset by the University of Maryland (Friedl et al. 2010). According to the cropland mask, the agricultural land area of the Yellow River, Huaihe River and Haihe River basin accounted for 4.94, 56.25 , and $38.24 \%$ of the total farmland area, respectively. The preprocessing of MODIS products including mosaic and projection conversion used MODIS Reprojection Tool (Version 4.0), and all the other processing was finished in the ENVI/IDL (Version 4.7/7.0) environment. All the images were resampled into $1 \mathrm{~km}$ spatial resolution using bilinear interpolation method.

\subsection{ENSO Index}

The Sea Surface Temperature Anomaly (SSTA) data of the sea surface temperature monitoring region Niño 3.4 $\left(5^{\circ} \mathrm{S}-5^{\circ} \mathrm{N}, 170-120^{\circ} \mathrm{W}\right)$ during January 1980 and June 2011 was used to define the ENSO events. Because of the sensitivity to small change in temperature, the National Oceanic and Atmospheric Administration (NOAA), National Centers for Environment Prediction (NCEP), Climate Prediction Center (CPC) and the International Research Institute for Climate and Society (IRI) unanimously take SSTA of this region to define the ENSO events (Xu et al. 2009). In this study, the monthly SSTA series from the Extended Reconstructed Sea Surface Temperature (ERSSSTA v3b) dataset of NOAA Climate Prediction Center was used,
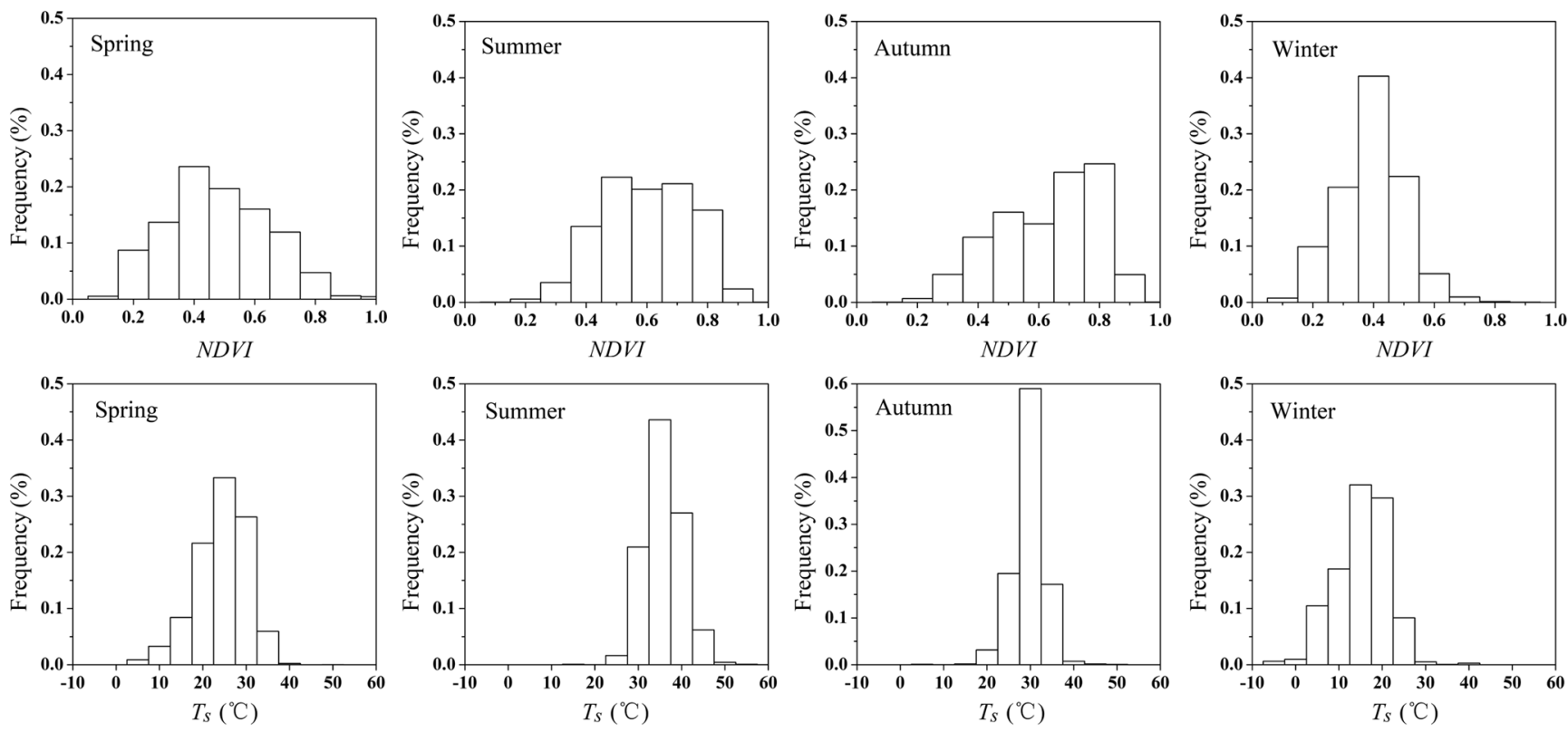

Fig. 3. Histogram of the constructed NDVI and $\mathrm{T}_{\mathrm{s}}$ image series of each season. 
and the time when SSTA is equal or greater than $0.5^{\circ} \mathrm{C}$ (or equal or less than $-0.5^{\circ} \mathrm{C}$ ) continues for 5 months indicates a El Niño (or La Niña) event (Xue et al. 2003; Smith et al. 2008). Finally, the yearly SSTA data series of nearly 31 years was built using the monthly data by calculating the arithmetic mean, where January was considered as a part of the winter of the previous year, which was consistent with the construction of yearly seasonal TVDI series.

\subsection{Analysis}

The Mann-Kendall test (Mann 1945), which is recommended by the World Meteorological Organization (WMO) and is widely used in areas such as meteorology and hydrology (Yue et al. 2002; Adnan and Atkinson 2011), was used to detect the trend and catastrophe of the long-term TVDI and ENSO indices for each season. The non-parametric Mann-Kendall test does not require samples to comply with a certain distribution. The method can exclude a small number of abnormal values and is applicable to the non-normal distributed data series. Mann-Kendall test statistics UF (forward of the statistics $U$ ) indicates an increasing trend when its value is positive, compared with the decreasing tendency in the contrary. When the absolute value of UF is greater than 1.96 , a significant trend may approach the $95 \%$ confidence level; if the absolute value is greater than 2.56, the measure of significance will increase to a confidence level of $99 \%$. The intersection of UF series and its reverse order statistics UB (backward of the statistics U) series indicate the catastrophe when it appears in between the two significant critical lines (Ma et al. 2007; Wei 2007). Sen's Slope (Sen 1968) was used to quantify the degree of multi-year trend, which is preferred over simple linear regression because linear regression is affected by missing data in the time series and certain distribution pattern of the dataset (Yin et al. 2011).
In addition, the Maximum Entropy Spectrum Analysis (MESA; Burg 1967) and Cross Spectrum Analysis (CSA; Mooers 1973) methods were applied to study the periodicity in TVDI and ENSO and the teleconnection between them. MESA has the advantages of high resolution so it is suitable for the relatively shorter sequences. The result of MESA is expressed as the spectrum density curve, and the cycle value corresponding to the curve peak is the significant cycle of the indices sequence. CSA can detect whether there is significant correlation between two time series in a certain cycle. The results of CSA include the coagulation spectrum and phase spectra. If there is a large coagulation spectrum at one cycle then the two time series related at this cycle with the phase spectra as the time difference length of the two sequences. All the spectrum estimates were compared using the $\mathrm{F}$ test to determine the significance level (95\% level). The correlation between TVDI and ENSO indices sequences was indicated using Pearson correlation coefficients and tested using t-tests to determine the significance level.

\section{RESULTS AND DISCUSSION}

\subsection{Spatiotemporal Variation in Agricultural Drought of the Huang-Huai-Hai Region for Nearly 30 Years}

The Mann-Kendall method was used to test the trend of the long-term seasonal TVDI images, and the spatial distribution of Sen's Slope of TVDI was shown in Fig. 4, which also indicated the tendency of the agricultural drought degree. The area with a significant decrease in drought was larger than the area with the upward trend in the HuangHuai-Hai region in each season over the past 30 years. Especially in winter, the area of drought significantly reduced was the highest among the four seasons, while the area of drought significantly increased was the lowest. There was an increasing trend in drought for the four seasons. The minimum area of drought decreased of the whole farmland in

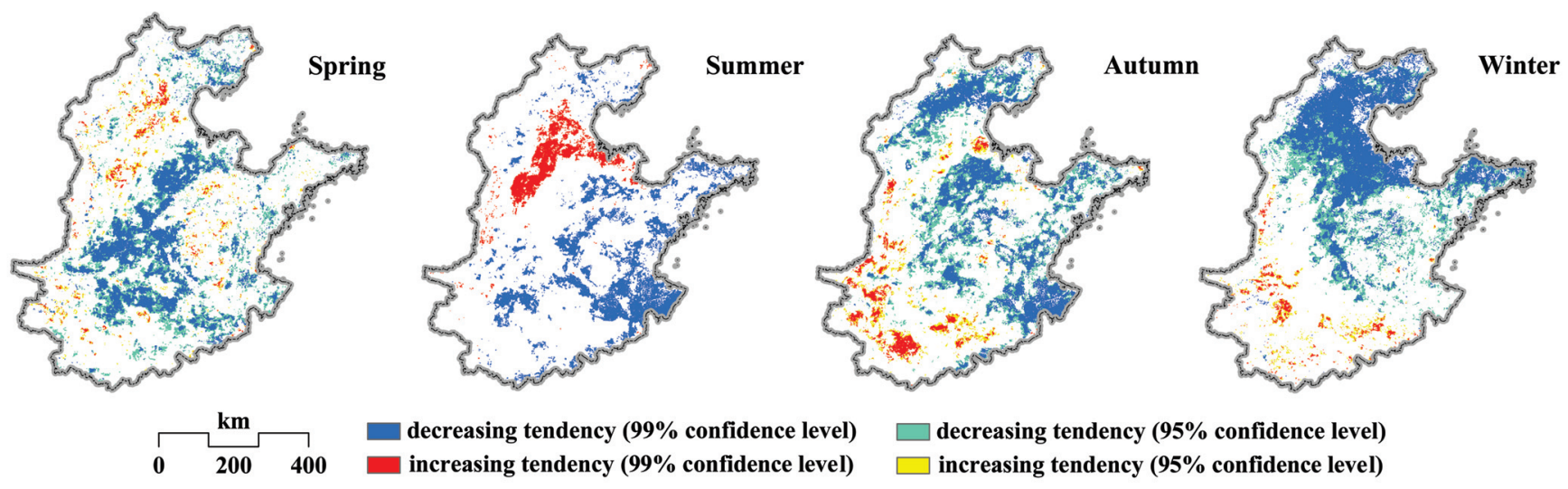

Fig. 4. Tendency (Sen's Slope) distribution of TVDI values of the Huang-Huai-Hai region from August 1981 to June 2011 using Mann-Kendall test for each season. 
the four seasons appeared in spring. All the proportion of the area of TVDI values significantly varied occupying farmland of the study area and each basin is shown in Table 1 .

At the same time, the overall regional average TVDI values were calculated in accordance with the following regions: the whole region and the three sub-regions. On the basis of the average TVDI series, the overall regional trend of agricultural drought was also evaluated with the
Mann-Kendall test. The results show that (Table 2) there were significant decreasing trends (99\% confidence level) of the whole region and each basin in the spring, summer and autumn seasons. In winter, there was a decreasing trend (significance level 99\%) in the Haihe River basin, while showing a significant decrease (significance level 95\%) for the whole region and the Yellow River basin, but no significant trend in the average TVDI in Huaihe River basin.

Table 1. The proportion of the area of TVDI values significantly changed from August 1981 to June 2011 using Mann-Kendall test occupied the farmland of the entire Huang-Huai-Hai region and each basin [Unit: \%].

\begin{tabular}{|c|c|c|c|c|c|c|}
\hline Region & Trend & Confidence level & Sping & Summer & Autumn & Winter \\
\hline \multirow{4}{*}{ Whole Huang-Huai-Hai region } & \multirow{2}{*}{ Increasing } & $99 \%$ & 2.71 & 9.01 & 5.32 & 2.61 \\
\hline & & $95 \%$ & 7.04 & 12.74 & 10.49 & 5.56 \\
\hline & \multirow{2}{*}{ decreasing } & $99 \%$ & 20.98 & 26.32 & 27.41 & 37.67 \\
\hline & & $95 \%$ & 38.01 & 46.01 & 47.46 & 55.13 \\
\hline \multirow{4}{*}{ Yellow River basin } & \multirow{2}{*}{ Increasing } & $99 \%$ & 1.10 & 2.24 & 5.80 & 6.71 \\
\hline & & $95 \%$ & 5.09 & 5.56 & 14.65 & 12.78 \\
\hline & \multirow{2}{*}{ decreasing } & $99 \%$ & 53.54 & 29.11 & 32.46 & 22.69 \\
\hline & & $95 \%$ & 72.39 & 56.05 & 58.79 & 51.33 \\
\hline \multirow{4}{*}{ Huaihe River basin } & \multirow{2}{*}{ Increasing } & $99 \%$ & 1.72 & 0.70 & 6.54 & 3.47 \\
\hline & & $95 \%$ & 5.10 & 1.71 & 12.38 & 7.77 \\
\hline & \multirow{2}{*}{ decreasing } & $99 \%$ & 19.61 & 39.27 & 22.03 & 13.12 \\
\hline & & $95 \%$ & 38.59 & 63.27 & 40.08 & 28.02 \\
\hline \multirow{4}{*}{ Haihe River basin } & \multirow{2}{*}{ Increasing } & $99 \%$ & 4.32 & 22.05 & 3.52 & 0.79 \\
\hline & & $95 \%$ & 10.17 & 29.95 & 7.31 & 1.51 \\
\hline & \multirow{2}{*}{ decreasing } & $99 \%$ & 19.34 & 7.13 & 34.92 & 76.07 \\
\hline & & $95 \%$ & 32.97 & 19.70 & 57.13 & 96.12 \\
\hline
\end{tabular}

Table 2. The Slope of Mann-Kendall trend of the average value of seasonal TVDI of the whole Huang-Huai-Hai region and each basin from August 1981 to June 2011.

\begin{tabular}{|c|c|c|c|c|c|}
\hline Season & Index & Whole Huang-Huai-Hai region & Yellow River basin & Huaihe River basin & Haihe River basin \\
\hline \multirow{2}{*}{ Spring } & Sen's slope & $-0.004 * *$ & $-0.007 * *$ & $-0.005 * *$ & $-0.005 * *$ \\
\hline & $\mathrm{z}$ & -3.34 & -3.87 & -3.09 & -2.87 \\
\hline \multirow{2}{*}{ Summer } & Sen's slope & $-0.009 * *$ & $-0.011 * *$ & $-0.010 * *$ & $-0.007 * *$ \\
\hline & $\mathrm{z}$ & -4.62 & -4.62 & -4.62 & -3.94 \\
\hline \multirow{2}{*}{ Autumn } & Sen's slope & $-0.004 * *$ & $-0.005 * *$ & $-0.004 * *$ & $-0.006 * *$ \\
\hline & $\mathrm{z}$ & -3.16 & -3.09 & -2.98 & -3.12 \\
\hline \multirow{2}{*}{ Winter } & Sen's slope & $-0.004 *$ & $-0.004 *$ & --- & $-0.008 * *$ \\
\hline & $\mathrm{z}$ & -2.05 & -2.16 & -1.52 & -3.12 \\
\hline
\end{tabular}

Note: M-K: Mann-Kendall; Sen's slope: the Mann-Kendall Sen's slope; $z:$ the statistic value of Mann-Kendall test; * or **: this indicates that there is a significant trend of the time series at 95\% or $99 \%$ confidence level respectively; ---: this indicates that there is no significant trend of this time series. 
Finally, the Mann-Kendall catastrophe analysis (Fig. 5) and Maximum Entropy Spectrum Analysis (Fig. 6) were used to study the average TVDI sequences. The results showed that the inflection points of different TVDI series in each season varied and during the same season the catastrophe points of different TVDI series for different areas varied as well. The main cycles of the sequences were 2.5, 2.73, $3.3,3.75,10$, and $15 \mathrm{a}$, about $85 \%$ of which existed between 2 to 5 a. We also analyzed the results by season.

\subsubsection{Spring}

The decrease in agricultural drought area in the spring season was the minimum among the four seasons (38.01 and $20.98 \%$ of the total area of regional agricultural land at 95 and $99 \%$ confidence level respectively, as shown in Table 1). It was mainly concentrated in the middle HuangHuai-Hai region, including most parts of the Yellow River basin, middle Huaihe River basin and southern Haihe River basin (Fig. 4). And the area of drought increased in spring during nearly 30 years was mainly in the central of Haihe River basin, as well as scattering at the southwestern and eastern parts of Huaihe River basin. It can be seen from Table 2 that the 30-year average spring TVDI series of the entire region and the three basins included showed a downward tendency at $99 \%$ confidence level with the Sen's slope value at about -0.005 . As shown in Fig. 5, the catastrophe point of the spring average TVDI sequence of the entire region appeared in 1996, with a significant decreasing trend at $95 \%$ confidence level after 2001. And the turning points of the spring average TVDI series of the Yellow, Huaihe and Haihe River basins occurred at 1999, 1999 and 1995 separately, and the decreasing tendency ( $95 \%$ confidence level) began from 2001, 2003 and 2002 respectively. The results of MESA showed that there were only the main cycles of the spring average TVDI series of Huaihe River basin with the value 2.5 and $5 \mathrm{a}$, while there was no cycle of the other sequences.

\subsubsection{Summer}

As shown in Fig. 4, agricultural drought in this region significantly reduced in summer over the past 30 years assumed highly distributed in the most parts of Yellow River basin and Huaihe River basin, and north of Haihe River ba$\sin$. The area of agricultural drought had the most significant upward tendency in summer in the recent 30 years among the four seasons (12.74 and $9.01 \%$ at 95 and $99 \%$ confidence level separately shown as Table 1). It mainly concentrated in south-central of Haihe River basin and a few in Yellow and Huaihe River basin. During the recent 30 years, the average summer TVDI series of the entire region and the three basins all showed a decreasing trend at $99 \%$ confidence level with the Sen's slope value of about -0.01 (Table
2). The Mann-Kendall test statistics shown in Fig. 5 had their catastrophe points at 1997, 1997, 1998 and 2000 for the whole region and the Yellow, Huaihe and Haihe River basin as shown respectively, and had a significantly downward tendency (95\% confidence level) after 1997, 1998, 2000 and 2002. The results of MESA showed that there was no cycle of the summer average TVDI sequence in Huaihe River basin, while the cycle of the summer TVDI series in the whole region was $2.5 \mathrm{a}$ and the cycles in the Yellow and Haihe River basin were both 2.73 a.

\subsubsection{Autumn}

During the recent 30 years, the area TVDI in autumn significantly reduced was mainly located in the north and southeast of Haihe River basin, east of Yellow and Huaihe River basin (Fig. 4). And the area the autumn TVDI series assumed upward tendency was mainly at the central of Haihe River basin and western Yellow and Huaihe River basin (Fig. 4). The average TVDI series of autumn in the whole region and the three basins all had a significant decreasing tendency at $99 \%$ confidence level with the Sen's slope value of about -0.005 . The catastrophe point of the autumn average TVDI sequence of the whole region appeared in 1997, with a significant decreasing trend at $95 \%$ confidence level after 2004, while the turning points of the autumn average TVDI series of the three basins occurred at 1999, 1999 and 1997 separately, and the decreasing tendency (95\% confidence level) began from 2005, 2005 and 2004 respectively (as shown in Fig. 5). According to the results of MESA, the autumn TVDI series of the whole region and the three basins all had a 5 a main cycle.

\subsubsection{Winter}

The largest area of regional agricultural drought significantly reduced in the last 30 years in winter (55.13 and $37.67 \%$ of the total cropland in this region at 95 and $99 \%$ confidence levels, respectively shown as in Table 1). The drought decreased region distributed in the vast majority of the Haihe River basin and the east of Yellow and Huaihe River basin (Fig. 4). While there was the least area of the drought significantly increased in winter of the four seasons (5.56 and 2.61\% at the confidence level of 95 and 99\%), which concentrated in the west of Yellow and Huaihe River basin, and very few in Haihe River basin. As shown in Table 2, only the winter average TVDI series of Haihe River basin was significantly reducing at $99 \%$ confidence with the Sen's slope -0.008 , while the decreasing trends of the winter TVDI series of the whole region and Yellow River basin reached $95 \%$ confidence and there was no significant change in the trend of the series of Huaihe River basin. As shown in Fig. 5, the catastrophe point of the winter average TVDI sequence of the entire region occurred in 2000, with 
(a) whole Huang-Huai-Hai region

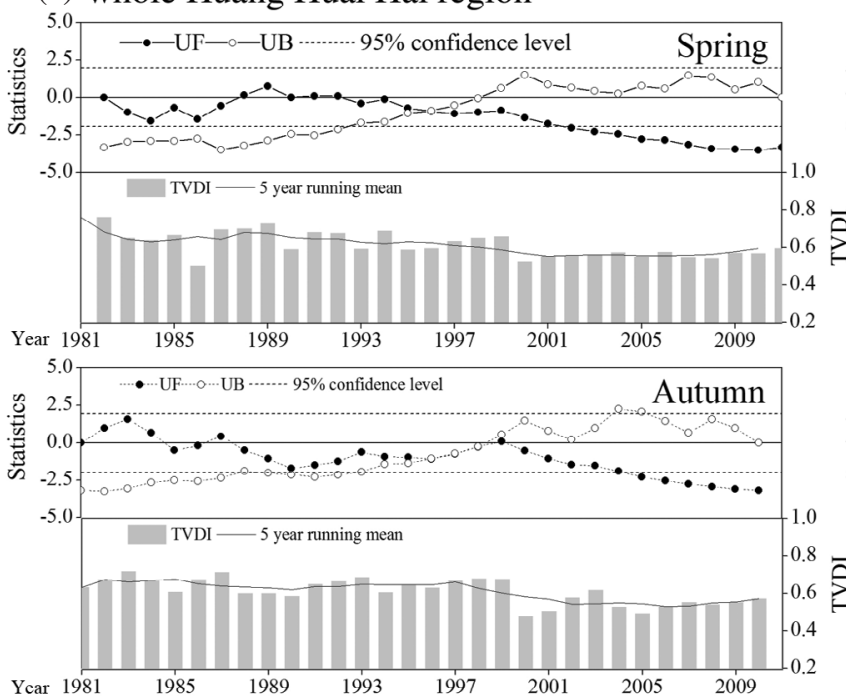

(b) Yellow River basin
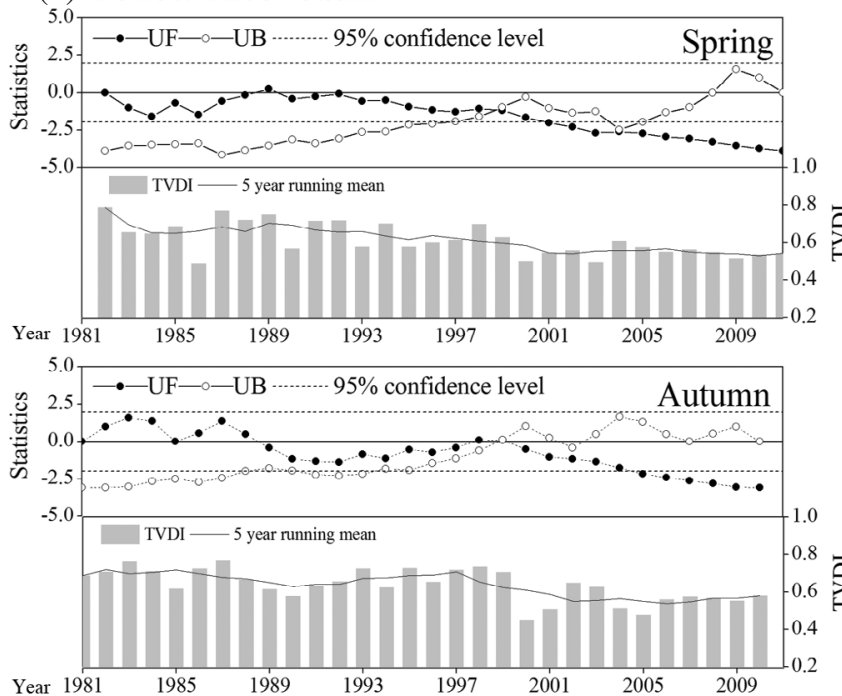

(c) Huaihe River basin
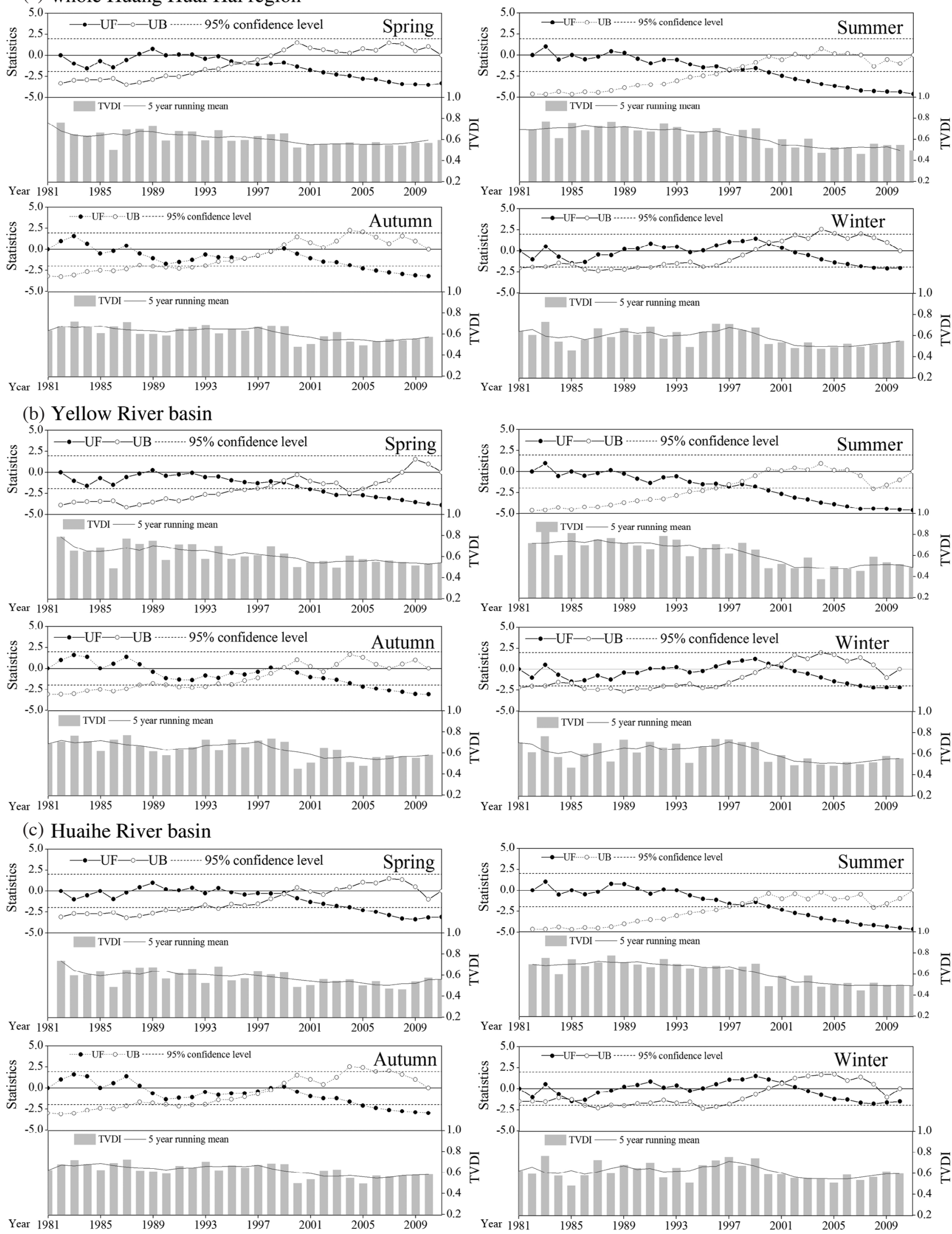

Fig. 5. Seasonal average TVDI values and their Mann-Kendall statistics of the whole Huang-Huai-Hai region and each basin from August 1981 to June 2011 . 
(d) Haihe River basin
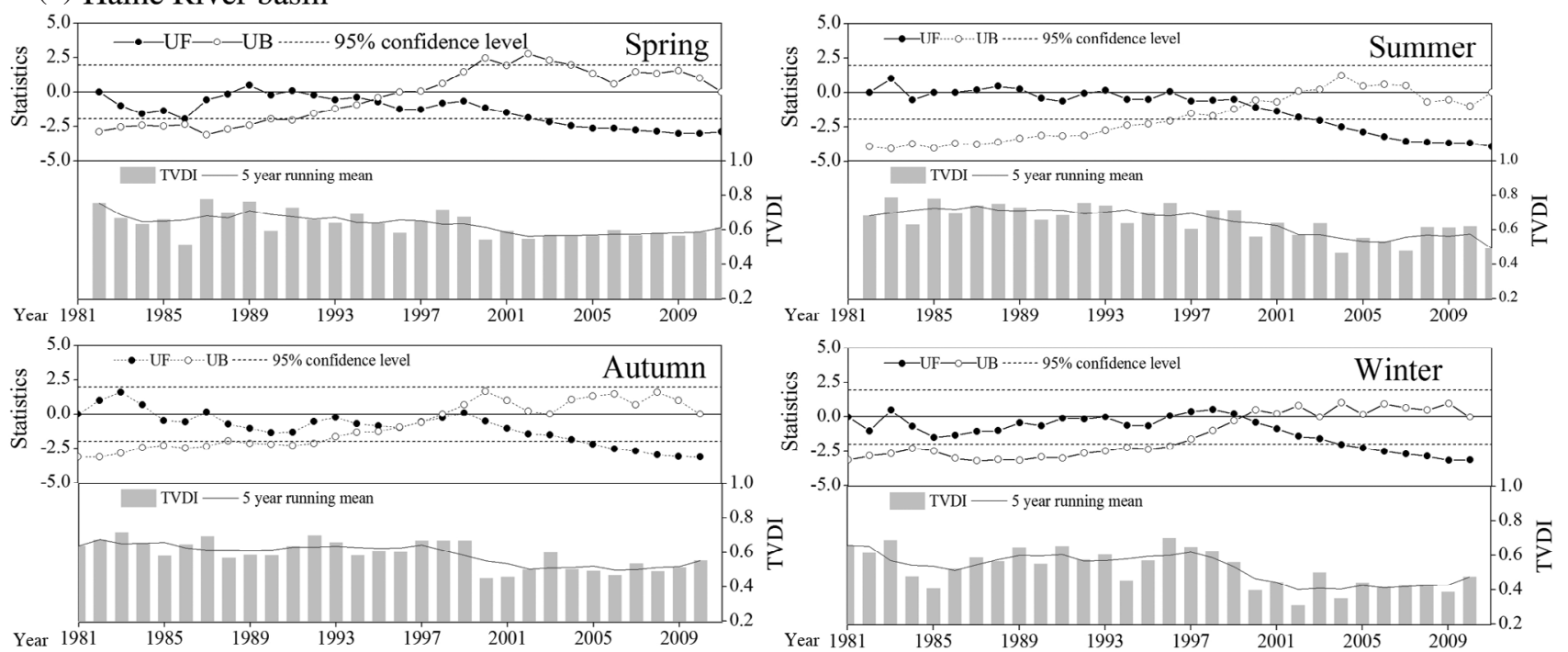

Fig. 5. (Continued)

(a) whole Huang-Huai-Hai region

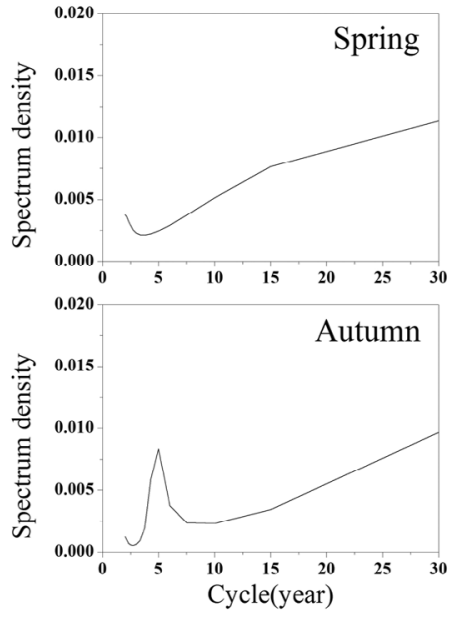

(c) Huaihe River basin
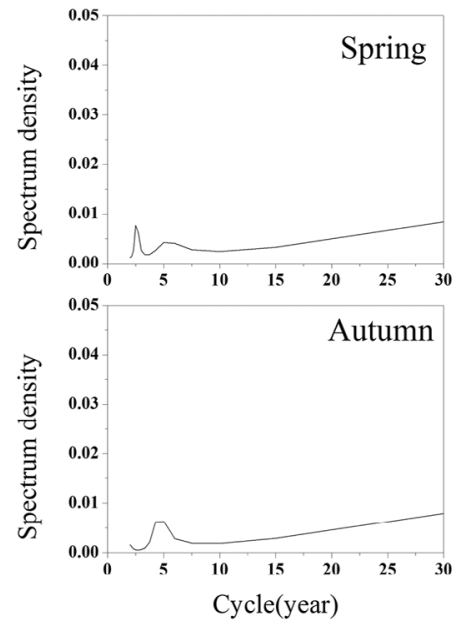
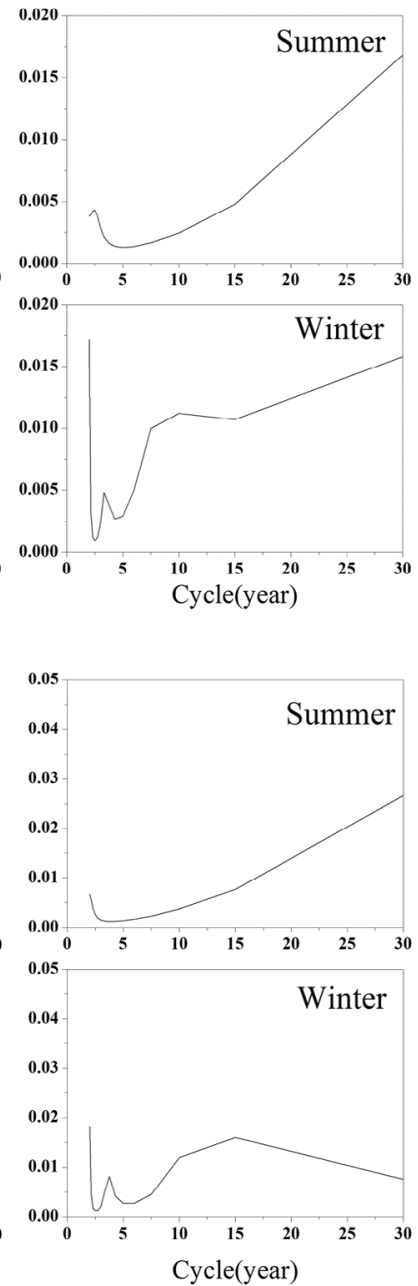

(b) Yellow River basin
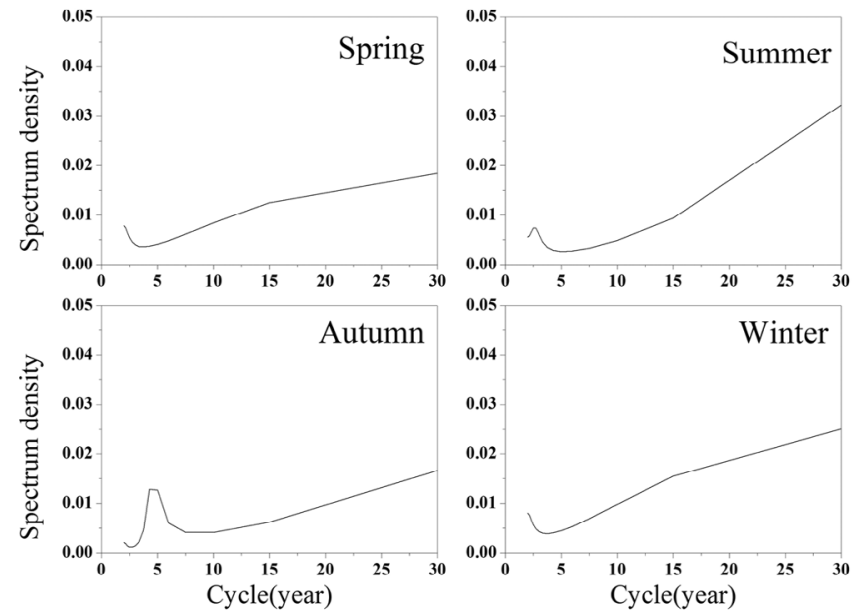

(d) Haihe River basin
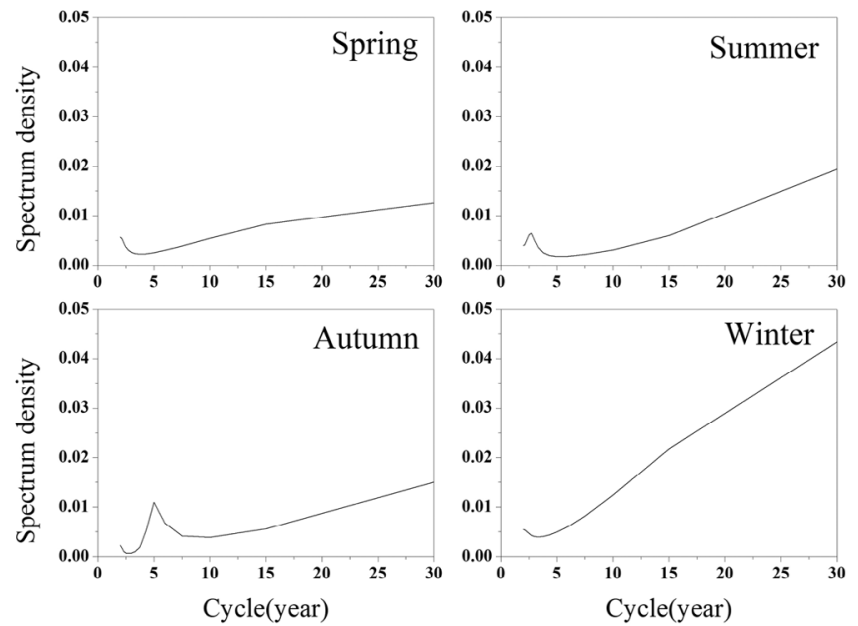

Fig. 6. Maximum entropy spectrum analysis of seasonal average TVDI values of the whole Huang-Huai-Hai region and each basin from Augest 1981 to June 2011. 
a significant decreasing trend at $95 \%$ confidence level after 2007. The turning points of the winter average TVDI series of the Yellow, Huaihe and Haihe River basins occurred at 2000, 2001 and 1999 separately, and the decreasing tendency (95\% confidence level) began from 2007 and 2004 for the Yellow and Haihe River basin respectively, while there was no significant trend in the Huaihe River basin. The results of MASE of winter TVDI sequences showed that there were primary cycles valued 3.3 and 10 a of the whole region, cycles of 3.75 and 15 a of the Huaihe River basin, and no significant cycle of the Yellow and Haihe River basin.

\subsection{Variation of ENSO Index in Nearly 30 Years}

According to the standard of NOAA Climate Prediction Center, an El Niño (or La Niña) event is defined as the SSTA $\geq 0.5^{\circ} \mathrm{C}$ (or $\leq-0.5^{\circ} \mathrm{C}$ ) last for over 5 months. Therefore, there were $9 \mathrm{El}$ Niño events and $6 \mathrm{La}$ Niña events from 1980 to 2011 . The extreme value and the accumulated value of Sea Surface Temperature (SST) during the event durations were used to classify the ENSO events degree. According to the criteria shown in the earlier study (Xu et al. 2009) which divided the ENSO events into five grades, in- cluding very weak, weak, moderate, strong and very strong. As a result, there were very strong El Niño events occurring between May 1982 and June 1983, and between May 1997 and May 1998. Strong El Niño events happened in the period of September 1986 to January 1988, and May 1991 to June 1992. Meanwhile, there were strong La Niña events between July 1998 and June 2000. It can be seen from Figs. $7 \mathrm{a}$ and $\mathrm{b}$, the frequency and intensity of El Niño events were both higher than La Niña events, and the results of Mann-Kendall test of SSTA series in the nearly 30 years showed that there was no significant tendency and catastrophe point of it (95\% confidence level). As shown in Fig. 7c, there was a 3.75 a primary cycle of the SSTA sequence from 1980 to 2010, consistent with previous results (Tudhope et al. 2001) 2.5 to 7 a cycle of ENSO indicators.

\subsection{Response of Agricultural Drought Spatiotemporal Variation to ENSO Events}

\subsubsection{Correlation Analysis of TVDI and ENSO Indicators}

The area of TVDI image and SSTA series significantly correlated at 95\% confidence level was very small (1.57 $6.88 \%$ in each season), so the $80 \%$ confidence level was (a) Annual

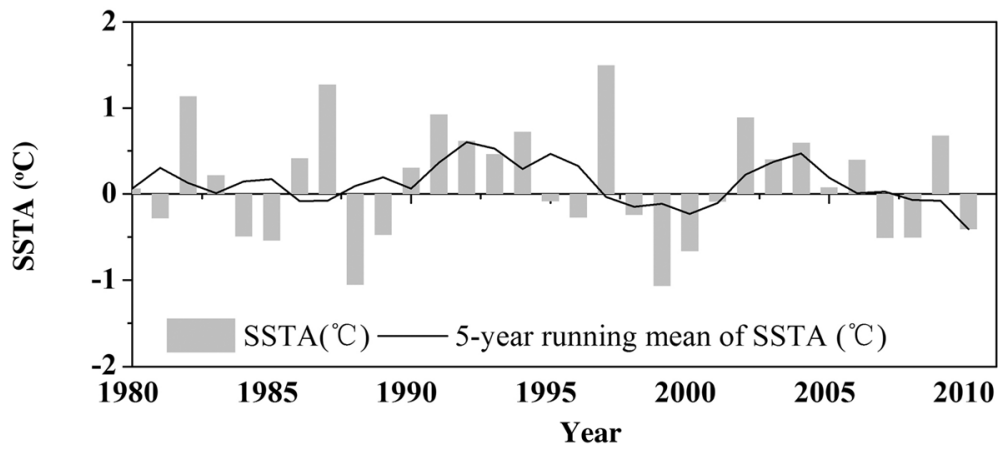

(c) MESA of SSTA

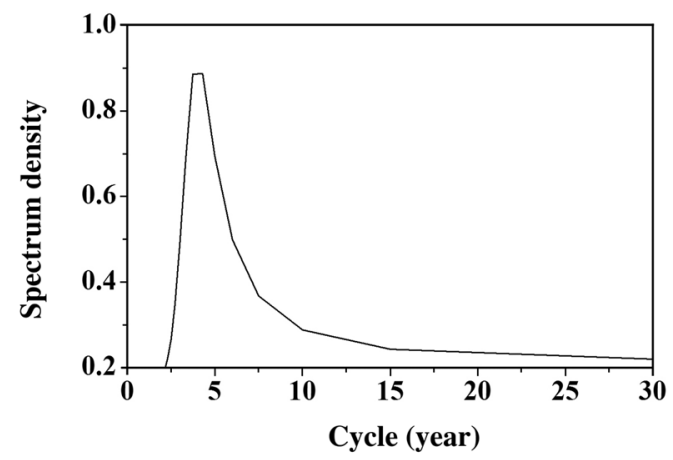

(b) Monthly

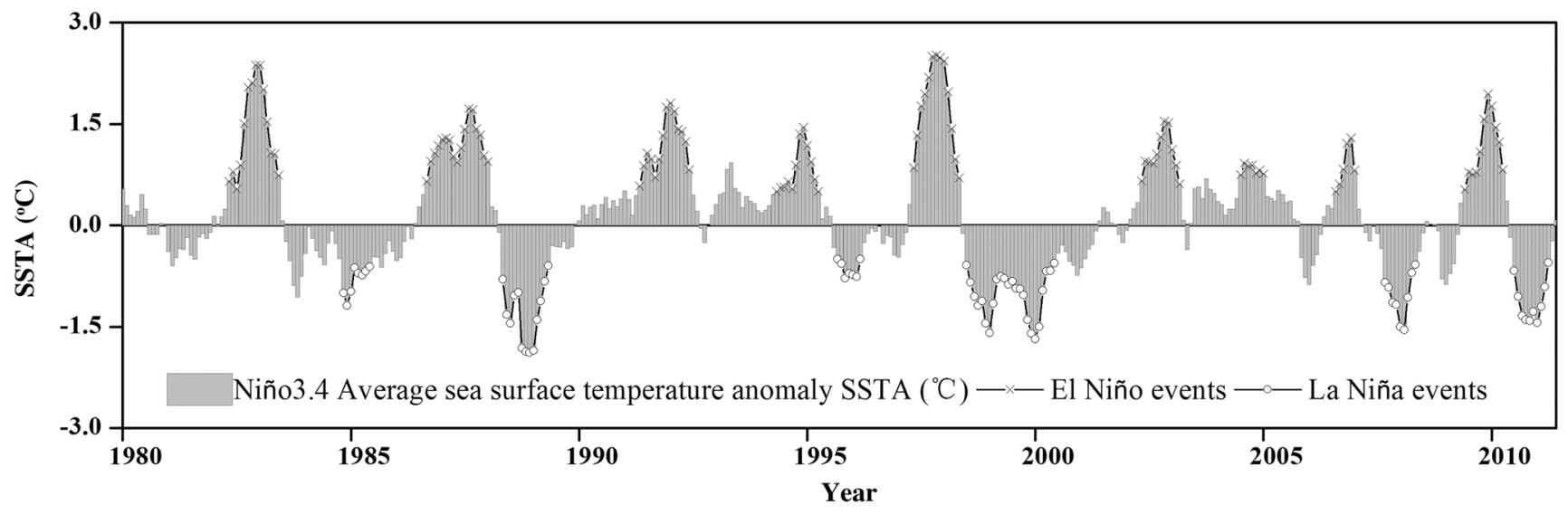

Fig. 7. Distribution of annual (a) and monthly (b) SSTA from January 1980 to June 2011 and maximum entropy spectrum analysis (c) of annual SSTA values. 
used to show the spatial distribution. Figure 8 showed the distribution of the correlation (linear pearson correlation coefficient) between the TVDI image series and SSTA sequence of each season from 1982 to 2010, where the red region indicated the significantly (80\% confidence level) positive relation which accounted for $12.81 \%$ (spring), $13.68 \%$ (summer), $12.43 \%$ (autumn) and $20.73 \%$ (winter) of the whole region, while the blue region indicated the negative correlation which occupied $13.97 \%$ (spring), $12.68 \%$ (summer), $15.39 \%$ (autumn) and $12.27 \%$ (winter). Specifically, in spring, the positively correlated region was higher in the Yellow and Huaihe River basin while the Haihe River showed a negative correlation. For the entire region, the positive correlation region was mainly concentrated in the east-west, while the negative one was in the north-south. In summer, the positively correlated region was mainly concentrated in the southwest and the negatively relevant region was concentrated in the north-central of the Huang-HuaiHai region, in which the positive correlation area accounted for $20.31 \%$ and the negative one accounted for $8.40 \%$ of the Huaihe River basin, the positive correlation region only accounted for $3.48 \%$ and the negative one accounted for $19.17 \%$ of the Haihe River basin, and the positively and negatively related regions had a similar percentage in the Yellow River basin. In autumn, the regional TVDI and SSTA correlation significantly decreased. The highest correlation region in the three basins was the Haihe River basin (18.64 and $19.97 \%$ of the cropland in Haihe River basin for the positive and negative correlations separately), and the Huaihe River basin had a relatively larger area of the negative correlation region occupied $11.94 \%$ of the farmland of this region, while the areas of the positive and negative correlation region were similar in the Yellow River basin as well. In winter, the region TVDI and SSTA were significantly positively related, especially in the Haihe River basin (accounting for $48.03 \%$ of the cropland of this region), and the region negatively correlated was mainly in the south and east of Huaihe River basin (accounting for $20.77 \%$ of the cropland of this region), the region significantly related in the Yellow River basin was less than $10 \%$. In general, the correlations between TVDI and SSTA were lower, probably because agricultural drought is a product of complex landatmosphere processes and can be influenced by a variety of environmental and human factors. Moreover, ENSO events are also a product of complicated ocean-atmosphere process. Therefore, the study above could only show the teleconnection relationship between agricultural drought and ENSO indices in the research area over the past 30 years.

\subsubsection{Correlation Analysis of TVDI and ENSO Indicator Cycle}

The drought indices for each basin in this region in each season significantly decreased, and the catastrophe points appeared at the end of the $20^{\text {th }}$ century. This result may be associated with the numbers of the occurrence of strong and very strong ENSO events in 1980 to 1990's and the relatively lower intensity of ENSO events since the $21^{\text {st }}$ century. In addition, there were multiple primary cycles of the average TVDI sequences of each season, in which 2.5 to 5 a accounted for $85 \%$ of all the cycles while the rest were 10 and 15 a. The $2.5 \sim 5$ a cycle of TVDI series was consistent with the cycle of ENSO indicator, while the 10 and 15 a cycle was the reflection of interdecadal variation (Wei 2004). In summary, the variation in agricultural drought in the Huang-Huai-Hai region in the recent 30 years was closely correlated with ENSO events as far as cycle analysis was concerned.

Table 3 showed the results of CSA of the average TVDI series of each season in the whole region and the three basins in it and the SSTA sequence, where the relatively larger coagulation spectrum values existed at the cycles of 2.33 , $2.55,2.80,4.00,4.67,5.60,7.00$, and 9.33 a (95\% confidence level), while there was a difference of cycles of TVDI

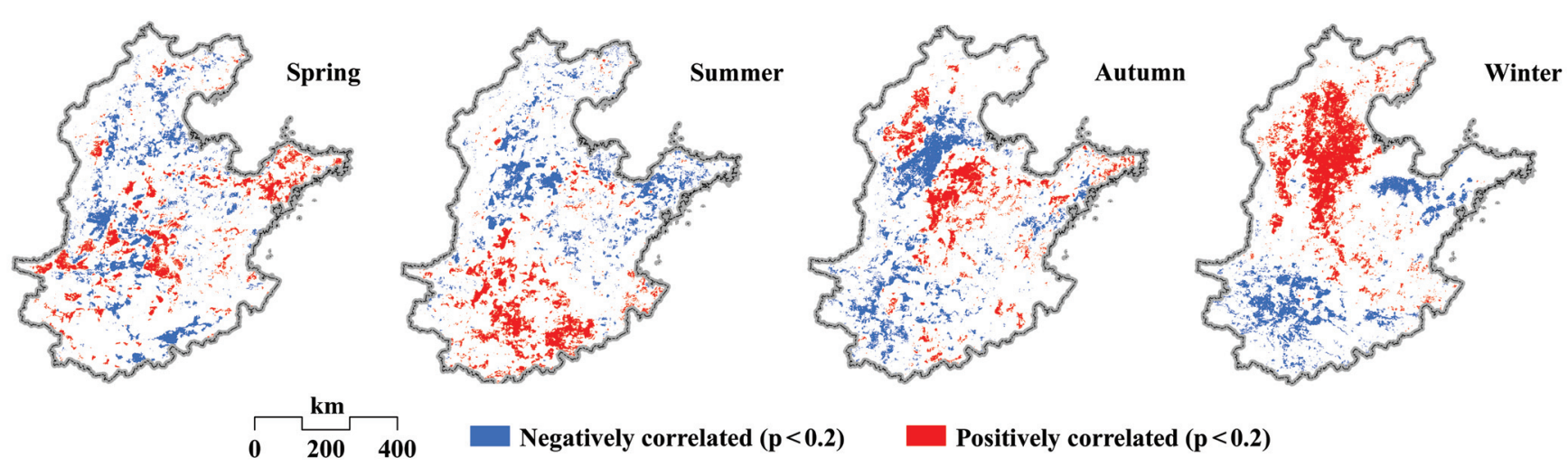

Fig. 8. Linear Pearson correlation distribution of annual TVDI series for each season and SSTA series of the Huang-Huai-Hai region from 1982 to 2010 . 
Table 3. Seasonal average TVDI values of the whole Huang-Huai-Hai region and each basin and annual SSTA from 1982 to June 2010.

\begin{tabular}{|c|c|c|c|c|c|c|c|c|c|c|c|c|}
\hline \multirow{2}{*}{ Region } & \multicolumn{3}{|c|}{ Spring } & \multicolumn{3}{|c|}{ Summer } & \multicolumn{3}{|c|}{ Autumn } & \multicolumn{3}{|c|}{ Winter } \\
\hline & $\mathbf{T}$ & $\mathbf{R}$ & $\mathbf{L}$ & $\mathbf{T}$ & $\mathbf{R}$ & $\mathbf{L}$ & $\mathbf{T}$ & $\mathbf{R}$ & $\mathbf{L}$ & $\mathbf{T}$ & $\mathbf{R}$ & $\mathbf{L}$ \\
\hline \multirow{5}{*}{ Whole Huang-Huai-Hai region } & $4.67 *$ & 0.98 & -1.15 & $7.00 *$ & 2.09 & -1.11 & $2.33 *$ & 1.36 & 0.49 & $2.55^{*}$ & 1.11 & -0.22 \\
\hline & $5.60 *$ & 0.97 & 1.39 & $5.60 *$ & 1.20 & -0.98 & $7.00 *$ & 0.99 & -0.56 & $2.33^{*}$ & 0.93 & -0.27 \\
\hline & $4.00 *$ & 0.86 & 0.77 & $4.67 *$ & 1.07 & -0.87 & $5.60^{*}$ & 0.98 & -0.57 & $4.67 *$ & 0.90 & -0.39 \\
\hline & & & & & & & $4.67 *$ & 0.89 & -0.69 & & & \\
\hline & & & & & & & $4.00 *$ & 0.82 & -0.84 & & & \\
\hline \multirow{6}{*}{ Yellow River basin } & $5.60^{*}$ & 0.98 & -1.27 & $9.33^{*}$ & 1.31 & 0.79 & $2.55^{*}$ & 1.79 & -0.22 & $5.60 *$ & 0.99 & -0.37 \\
\hline & $4.67^{*}$ & 0.98 & -0.99 & $7.00 *$ & 1.30 & -1.12 & $7.00 *$ & 1.10 & -0.43 & $4.67 *$ & 0.99 & -0.33 \\
\hline & & & & $5.60 *$ & 1.06 & -0.75 & $5.60 *$ & 0.93 & -0.57 & $2.33^{*}$ & 0.93 & -0.41 \\
\hline & & & & $4.67 *$ & 0.96 & -0.75 & $4.67 *$ & 0.87 & -0.72 & $2.55^{*}$ & 0.84 & -0.41 \\
\hline & & & & & & & $2.80 *$ & 0.85 & -0.19 & & & \\
\hline & & & & & & & $4.00 *$ & 0.84 & -0.84 & & & \\
\hline \multirow{7}{*}{ Huaihe River basin } & $4.67 *$ & 0.96 & -1.06 & $5.60 *$ & 1.12 & -1.09 & $2.55^{*}$ & 1.39 & -0.48 & $2.55^{*}$ & 0.86 & -0.25 \\
\hline & $5.60 *$ & 0.94 & -1.25 & $7.00^{*}$ & 1.09 & -1.36 & $7.00^{*}$ & 1.06 & -0.31 & & & \\
\hline & $2.55^{*}$ & 0.85 & 0.11 & $4.67 *$ & 1.00 & -0.92 & $2.80^{*}$ & 1.00 & -0.23 & & & \\
\hline & & & & & & & $5.60 *$ & 0.95 & -0.52 & & & \\
\hline & & & & & & & $2.33^{*}$ & 0.90 & 0.47 & & & \\
\hline & & & & & & & $4.67 *$ & 0.88 & -0.70 & & & \\
\hline & & & & & & & $4.00^{*}$ & 0.85 & -0.80 & & & \\
\hline \multirow{4}{*}{ Haihe River basin } & $5.60 *$ & 0.97 & -1.40 & $7.00^{*}$ & 2.51 & 0.25 & $5.60 *$ & 0.98 & -0.63 & $2.55^{*}$ & 0.98 & -0.18 \\
\hline & $4.67 *$ & 0.97 & -1.06 & $5.60 *$ & 1.25 & -0.80 & $4.67 *$ & 0.88 & -0.67 & $4.67^{*}$ & 0.96 & -0.33 \\
\hline & $4.00^{*}$ & 0.94 & -0.87 & $4.67 *$ & 1.21 & -0.82 & $7.00 *$ & 0.86 & -0.84 & $2.33^{*}$ & 0.94 & -0.16 \\
\hline & & & & $9.33 *$ & 0.87 & -0.75 & & & & $5.60 *$ & 0.87 & -0.44 \\
\hline
\end{tabular}

Note: T: Cycle; R: Coagulation spectrum; L: Phase spectrum; *: 95\% significant level of F test.

and SSTA series ranged from -1.40 to 1.39 . The cycles between 2.5 and 7 a accounted for $96.55 \%$ of all the cycles corresponding to the high cohesion spectrum values. Therefore the patterns in TVDI in the Huang-Huai-Hai region and ENSO were significantly correlated with the value 2.5 to $7 \mathrm{a}$, while the TVDI cycles lagged behind SSTA cycles for 0.16 to 1.40 a or were ahead of SSTA cycles for 0.11 to $1.39 \mathrm{a}$, the vast of which was lagging (89.29\%). Eastern Asian summer and winter monsoons play an important role in the precipitation and temperature in East China ( $\mathrm{He}$ et al. 2007), and they are influenced by ENSO through the strength of the subtropical high in the western Pacific region (Chen 2002; Li et al. 2010; Wang et al. 2010). The lag in response of the atmosphere to ocean heat changes and the formation of monsoon systems along with the impact on precipitation and temperature might possibly serve as the physical mechanism of the phenomenon mentioned above.

\section{CONCLUSIONS}

Remotely sensed TVDI image and average value series were used to reveal patterns in spatial and temporal variations of agricultural drought in the Huang-Huai-Hai region in China during the recent 30 years. The results show that the agricultural drought in this region generally shows a significant decreasing trend in all seasons. There was the maximum area of drought reducing and minimum area of drought increasing in winter as well as the relatively larger area of drought increasing in summer and a relatively smaller area of drought decreasing in spring. The significant decrease 
in agricultural drought in this region generally started from late $20^{\text {th }}$ century and early $21^{\text {st }}$ century. There is a periodicity of 2.5 to 7 a for the 30 -year TVDI series according to spectrum analysis.

Analyzed together with the ENSO indicators, the variation in TVDI seems related to the high frequency and intensity of ENSO events in 1980s and 1990s and their weakening since $21^{\text {st }}$ century. The 2.5 to 7 a cycle of TVDI series in most regions was consistent with the 3.75 a cycle of ENSO indicator in the 30 years, which was also in line with the generally considered 2.5 to 7 a cycle of ENSO events (Tudhope et al. 2001). TVDI series significantly correlated with ENSO indices in the 2.5 to 7 a cycle, while the former were mainly delayed 0.16 to 1.40 a from the latter. Thus the patterns in agricultural drought in this region during nearly 30 years are closely related with ENSO events. However, from the point of view of spatial distribution of the TVDI and ENSO indicator correlation, the area reaching relatively high significance test level was small. We found large areas which were positively related in the winter and negative related in the autumn.

The results of this study show that the relationship between agricultural drought and ENSO indices in the HuangHuai-Hai region over more than 30 years. To study the complex physical processes in a more detailed manner will require numerical simulation models coupled with climate models, possibly considering other environmental and human factors which were not included in this study.

Acknowledgements The Pathfinder AVHRR Land (PAL) dataset was provided by the Environmental and Ecological Science Data Center for West China, National Natural Science Foundation of China (http://westdc.westgis.ac.cn). The MODIS dataset was downloaded from NASA Goddard Earth Sciences Data and Information Services Center (GESDISC) (ftp://e4ft101u.ecs.nasa.gov). ERSSTA v3b dataset was obtained from NOAA NESDIS National Climate Data Center (http://www.ncdc.noaa.gov/ersst). This study is supported by the National Program on Key Basic Research Project of China (No. 2010CB951503), Graduate Student Innovation Project of Jiangsu Province, China (No. CXLX11_0023), National Science and Technology Major Project (Grant No. 30-Y20A01-9003-12/13, China) and National Science Foundation of China (Grant No. 41201438). The authors wound like to thank the reviewers for their comments. We are also grateful to Dr. Wenjuan Zhu of University of Leeds and Dr. Yuanli Zhu of Nagoya University for checking the English in our paper.

\section{REFERENCES}

Adnan, N. A. and P. M. Atkinson, 2011: Exploring the impact of climate and land use changes on streamflow trends in a monsoon catchment. Int. J. Climatol., 31,
815-831, doi: 10.1002/joc.2112. [Link]

Bates, B. C., Z. W. Kundzewicz, S. Wu, and J. P. Palutikof (Eds.), 2008: Climate Change and Water. IPCC Technical Paper VI, International Panel on Climate Change (IPCC) Secretariat, Geneva, $210 \mathrm{pp}$.

Becker, F. and Z. L. Li, 1990: Towards a local split window method over land surface. Int.J.Remote Sens., 11, 369-393, doi: 10.1080/01431169008955028. [Link]

Burg, J. P., 1967: Maximum entropy spectral analysis. The $37^{\text {th }}$ Annual International Meeting, Society of Exploration Geophysics, Oklahoma City, October 31.

Chen, J., C. Wang, H. Jiang, L. Mao, and Z. Yu, 2011: Estimating soil moisture using Temperature-Vegetation Dryness Index (TVDI) in the Huang-huai-hai (HHH) plain. Int. J. Remote Sens., 32, 1165-1177, doi: 10.10 80/01431160903527421. [Link]

Chen, W., 2002: Impacts of El Niño and La Niña on the cycle of the East Asian winter and summer monsoon. Chin. J. Atoms. Sci., 26, 595-610. (in Chinese)

Cihlar, J., D. Manak, and M. D'Iorio, 1994: Evaluation of compositing algorithms for AVHRR data over land. IEEE Trans. Geosci. Remote Sensing, 32, 427-437, doi: 10.1109/36.295057. [Link]

Cihlar, J., H. Ly, Z. Li, J. Chen, H. Pokrant, and F. Huang, 1997: Multitemporal, multichannel AVHRR data sets for land biosphere studies - Artifacts and corrections. Remote Sens. Environ., 60, 35-57, doi: 10.1016/S00344257(96)00137-X. [Link]

Cole, J. E., J. T. Overpeck, and E. R. Cook, 2002: Multiyear La Niña events and persistent drought in the contiguous United States. Geophys. Res. Lett., 29, 25-1-25-4, doi: 10.1029/2001GL013561. [Link]

Dai, A., 2011: Drought under global warming: A review. WIREs Clim. Change, 2, 45-65, doi: 10.1002/wcc.81. [Link]

Folland, C. K., T. N. Palmer, and D. E. Parker, 1986: Sahel rainfall and worldwide sea temperatures, 1901-85. $\mathrm{Na}$ ture, 320, 602-607, doi: 10.1038/320602a0. [Link]

Friedl, M. A., D. Sulla-Menashe, B. Tan, A. Schneider, N. Ramankutty, A. Sibley, and X. Huang, 2010: MODIS Collection 5 global land cover: Algorithm refinements and characterization of new datasets. Remote Sens. Environ., 114, 168-182, doi: 10.1016/j.rse.2009.08.016. [Link]

Giannini, A., R. Saravanan, and P. Chang, 2003: Oceanic forcing of Sahel rainfall on interannual to interdecadal time scales. Science, 302, 1027-1030, doi: 10.1126/science.1089357. [Link]

Giannini, A., M. Biasutti, and M. M. Verstraete, 2008: A climate model-based review of drought in the Sahel: desertification, the re-greening and climate change. Global Planet. Change, 64, 119-128, doi: 10.1016/j. gloplacha.2008.05.004. [Link]

He, J., J. Ju, Z. Wen, J. Lü, and Q. Jin, 2007: A review of re- 
cent advances in research on Asian monsoon in China. Adv. Atmos. Sci., 24, 972-992, doi: 10.1007/s00376007-0972-2. [Link]

Holben, B. N, 1986: Characteristics of maximum-value composite images from temporal AVHRR data. Int. J. Remote Sens., 7, 1417-1434, doi: 10.1080/01431168 608948945. [Link]

Lambin, E. F. and D. Ehrlich, 1996: The surface temperature-vegetation index space for land cover and landcover change analysis. Int. J. Remote Sens., 17, 463487, doi: 10.1080/01431169608949021. [Link]

Li, D. L. and H. Yao, 1991: The relationship between El Niño phenomena (1470-1979) and dryness and wetness of China. Arid Land Geogr., 14, 48-52. (in Chinese)

Li, H., A. Dai, T. Zhou, and J. Lu, 2010: Responses of East Asian summer monsoon to historical SST and atmospheric forcing during 1950-2000. Climate Dyn., 34, 501-514, doi: 10.1007/s00382-008-0482-7. [Link]

Lu, A. G., J. P. Ge, D. Q. Pang, Y. Q. He, and H. X. Pang, 2006: Asynchronous response of droughts to ENSO in China. J. Glacio. Geocry., 28, 535-542. (in Chinese)

Ma, Z. G. and C. B. Fu, 2007: Global aridification in the second half of the $20^{\text {th }}$ century and its relationship to large-scale climate background. Sci. China Ser. D, 50, 776-788, doi: 10.1007/s11430-007-0036-6. [Link]

Mann, H. B, 1945: Nonparametric tests against trend. Econometrica, 13, 245-259, doi: 10.2307/1907187. [Link]

Mooers, C. N. K, 1973: A technique for the cross spectrum analysis of pairs of complex-valued time series, with emphasis on properties of polarized components and rotational invariants. Deep Sea Res. Ocean. Abstr., 20, 1129-1141, doi: 10.1016/0011-7471(73)90027-2. [Link]

Moran, M. S., T. R. Clarke, Y. Inoue, and A. Vidal, 1994: Estimating crop water deficit using the relation between surface-air temperature and spectral vegetation index. Remote Sens. Environ., 49, 246-263, doi: 10.10 16/0034-4257(94)90020-5. [Link]

Nemani, R., L. Pierce, S. Running, and S. Goward, 1993: Developing satellite-derived estimates of surface moisture status. J. Appl. Meteorol., 32, 548-557, doi: 10.11 75/1520-0450(1993)032<0548:DSDEOS>2.0.CO;2. [Link]

Patel, N. R., R. Anapashsha, S. Kumar, S. K. Saha, and V. K. Dadhwal, 2009: Assessing potential of MODIS derived temperature/vegetation condition index (TVDI) to infer soil moisture status. Int. J. Remote Sens., 30, 23-39, doi: 10.1080/01431160802108497. [Link]

Power, S. B. and I. N. Smith, 2007: Weakening of the Walker Circulation and apparent dominance of El Niño both reach record levels, but has ENSO really changed? Geophys. Res. Lett., 34, L18702, doi: 10.1029/2007 GL030854. [Link]
Qi, S. H., C. Y. Wang, and Z. Niu, 2003: Evaluating soil moisture status in China using the Temperature/Vegetation Dryness Index (TVDI). J. Remote Sens., 7, 420427. (in Chinese)

Sandholt, I., K. Rasmussen, and J. Andsersen, 2002: A simple interpretation of the surface temperature/vegetation index space for assessment of surface moisture status. Remote Sens. Environ., 79, 213-224, doi: 10.1016/S00 34-4257(01)00274-7. [Link]

Sarachik, E. S. and M. A. Cane, 2010: The El Niño-Southern Oscillation Phenomenon, Combrige Univercity Press, Cambridge, UK, 384 pp.

Seager, R., R. Burgman, Y. Kushnir, A. Clement, E. Cook, N. Naik, and J. Miller, 2008: Tropical Pacific forcing of North American Medieval megadroughts: Testing the concept with an atmosphere model forced by coralreconstructed SSTs. J. Climate, 21, 6175-6190, doi: 10.1175/2008JCLI2170.1. [Link]

Sen, P. K., 1968: Estimates of the regression coefficient based on Kendall's tau. J. Am. Stat. Assoc., 63, 13791389, doi: 10.1080/01621459.1968.10480934. [Link]

Smith, T. M., R. W. Reynolds, T. C. Peterson, and J. Lawrimore, 2008: Improvements to NOAA's historical merged land - Ocean surface temperature analysis (1880-2006). J. Climate, 21, 2283-2296, doi: 10.11 75/2007JCLI2100.1. [Link]

Su, M. F. and H. J. Wang, 2007: Relationship and its instability of ENSO - Chinese variations in droughts and wet spells. Sci. China Ser. D, 50, 145-152, doi: 10.1007/s11430-007-2006-4. [Link]

Sun, L., F. Wang, and Q. Wu, 2010: Drought monitoring by remote sensing in winter-wheat-growing area of China. Trans. Chin. Soc. Agric. Eng., 26, 243-249. (in Chinese)

Tudhope, A. W., C. P. Chilcott, M. T. McCulloch, E. R. Cook, J. Chappell, R. M. Ellam, D. W. Lea, J. M. Lough, and G. B. Shimmield, 2001: Variability in the El Niño-Southern Oscillation through a glacial-interglacial cycle. Science, 291, 1511-1517, doi: 10.1126/ science.1057969. [Link]

Wang, B., Z. Wu, C. P. Chang, J. Liu, J. Li, and T. Zhou, 2010: Another look at interannual-to-interdecadal variations of the East Asian Winter Monsoon: The northern and southern temperature modes. J. Climate, 23, 1495-1512, doi: 10.1175/2009JCLI3243.1. [Link]

Wei, F. Y., 2004: Characterization of drought strength in North China and its climatic variation. J. Natl. Disaster, 13, 32-38. (in Chinese)

Wei, F. Y (Ed.), 2007: Modern Climate Statistics Diagnosis and Prediction Techniques ( $2^{\text {nd }}$ edition $)$, China Meteorological Press, Beijing, 69-72. (in Chinese)

Weng, B. S. and D. H. Yan, 2010: Integrated strategies for dealing with droughts in changing environment in China. Resour. Sci., 32, 309-316. (in Chinese) 
Xu, C. W., W. Wang, J. S. Ma, and D. Y. Xu, 2009: ENSO events during 1951-2007 and their characteristic indices. J. Natl. Disaster, 18, 18-24. (in Chinese)

Xue, Y., T. M. Smith, and R. W. Reynolds, 2003: Interdecadal changes of 30-yr SST normals during 1871-2000. J. Climate, 16, 1601-1612, doi: 10.1175/1520-044216.10.1601. [Link]

Yin, H., Z. G. Li, Y. L. Wang, and F. Cai, 2011: Assessment of desertification using time series analysis of hypertemporal vegetation indicator in Inner Mongolia. Acta Geogr. Sin., 66, 653-661. (in Chinese)

Yue, S., P. Pilon, and G. Cavadias, 2002: Power of the Mann-Kendall and Spearman's rho tests for detecting monotonic trends in hydrological series. J. Hydrol., 259, 254-271, doi: 10.1016/S0022-1694(01)00594-7. [Link] 